\title{
Trafficked Women in Denmark-Falling through the cracks
}

\author{
Kira West
}

Please cite this article as: K West, 'Trafficked Women in Denmark-Falling through the cracks', Anti-Trafficking Review, issue 10, 2018, pp. 160-163, www.antitraffickingreview.org

The policy framework for combating human trafficking and protecting victims in Denmark does not match the reality faced by the majority of the migrant women arriving in the country. Especially in relation to women from African countries, the national legislation and regulations can be a source of frustration for agencies such as Reden International, which helps foreign women working in prostitution in Denmark, particularly victims of trafficking.

There are different groups of migrant women selling sex in Denmark. Many come from Thailand or Eastern Europe, but the majority of the women we meet are from Nigeria.

Nigerian women finance their hazardous journey from their home country by taking out loans, often from people in Europe or in Nigeria who promise good earnings. The loan finances their journey and counterfeit documents and might secure a job when they arrive. That is, if they are fortunate enough to make it across European borders.

Some of these migration stories include elements which align with the UN definition of trafficking, such as transportation, debt and deceit. However, others challenge the general understanding of human trafficking on which Danish legislation and interventions are based in one significant aspect-most of the time, the women have chosen to travel to Europe in the hope of a better life: a hope that is sometimes shattered.

When we at Reden International meet newly arrived Nigerian women, they often still believe that they will be able to pay off their debt and send money back home. After a while, the enormous pressure and harsh working conditions become clear. Many of the women have been cheated, threatened and experienced violence while working in the streets. They are under stress because of their low earnings and the high cost of living in Denmark. If they do not make enough money, some are threatened, with possible repercussions for their families back in Nigeria. We have heard examples of family houses being burnt down or family members being kidnapped. Many of them are also suffering from the effects of life as undocumented migrant women in rough street-based environments where they are subject to exploitation, violence and rape.

Women come anonymously to our night-time café (Natcafé), situated in a central location of the red-light district in Copenhagen, where we offer support and advice while they take a much-needed break. Adding to the stress of having to earn enough money to pay off their debts, the women also describe a constant fear of being caught by the police. Consequently, they do not seek help from the police or other authorities when they experience violent episodes. They do not trust the authorities and are afraid of being deported from Denmark as irregular migrants.

As a consequence, the women instead come to us. We have cleaned cigarette burns from their bodies at our Natcafé, and offered what support we can after injuries sustained from physical abuse and much more. We have asked them to describe the perpetrators in order to warn other women and send the information on to the police. However, because of their reluctance to contact the police, the people behind these criminal acts are very rarely reported. We find it unacceptable that these criminals have carte blanche to expose women to violence and then go free. Irrespective of whether or not they have the right papers, these women have a right to protection. They should be able to report perpetrators without fearing deportation.

The political response to migration in Denmark has increasingly focused on returning migrants to where they came from as soon as possible. In practice, the policies for victims of human trafficking follow the same approach, even though these people are extremely vulnerable and under great pressure, with very little ability to do anything about their situation. This policy makes it hard to help the women. 
Most commonly, the Danish authorities encounter migrant women through police raids on the streets or in apartments. After the women are taken in custody, a brief interview determines whether they qualify as trafficking victims or not. Despite international criticism, ${ }^{1}$ Denmark does not allow victims of human trafficking to remain in the country. Instead, they are granted a 30-day 'reflection period' to decide whether they will cooperate on preparing the repatriation. ${ }^{2}$ During this period they live at a shelter. If the women cooperate, the reflection period may be extended to three months. After three months, they are required to return to their home country.

A longer reflection period of at least six months would make it possible to develop a relationship of trust with the woman, find out what she thinks about her situation, who has exploited her and how, what she needs in order to have a sustainable life in her home country, and whether she will contribute to investigations and participate in any criminal proceedings against her traffickers or even consider repatriation. However, the provision of a reflection period and support should not depend on victims' cooperation with the criminal investigation. The Danish government has an obligation to protect victims of crime and not simply use them for the purpose of solving the crime.

We should not be blind to the fact that these women need to earn money. Today, they often refuse an offer of help because they have to earn money for their family back home and to repay their debt to the financiers or traffickers. They have no chance of this as things stand today. If they were allowed to earn money from day one of the reflection period, it is certain that more women would accept assistance and counselling.

More targeted interventions are also needed. Research shows that focusing on sustainable repatriation for those who actually want to return home is a much more valuable strategy than forced returns. Trafficked women who return voluntarily will be much more engaged in seeking a good life in their home country. Also, those who manage best in life after trafficking are those with good networks to return to. ${ }^{3}$

However, the current Danish anti-trafficking policies and the broader political climate on migration in the EU allows no opportunity for individual focus. Our point of departure is that everyone should be assisted and treated decently, irrespective of their residency status and trafficking story. Everyone should be able to go to hospital when they are ill and to the police if they have been subjected to violence or rape.

We believe that in Denmark and across Europe, there is a need for a different, more realistic and humanitarian perspective, a perspective appropriate to the current migration patterns, which takes into account women's reality. Initiatives must focus on the individual and consider the situation in which they find themselves. We believe these initiatives should include provision of longer reflection and recover periods, the possibility to earn money, better access to authorities, and collaborations between victims and authorities built on trust and a prioritised concern for victim protection over criminal prosecution. This is vital if the government truly wants to reach and help a larger group of these extremely exposed and vulnerable victims of severe exploitation or human trafficking.

Kira West is Principal of Reden International (RI) - one of the main independent private institutions in Denmark supporting women who are victims of human trafficking. RI provides support for foreign women in prostitution, offering guidance, healthcare, legal consultancy, and social care. RI runs a counselling centre for foreign women, the Night Café, does outreach work in and outside Copenhagen, and runs a safe house for foreign women who are victims of trafficking. Email: kw@reden.dk

1 GRETA, Report concerning the implementation of the Council of Europe Convention on Action against Trafficking in Human Beings by Denmark - Second Evaluation Round, Council of Europe, 2016, retrieved 12 March 2018, https:/ / rm.coe.int/16806662af.

2 Danish Government, Action Plan to Combat Trafficking in Human Beings 2015-2018, The Ministry for Children, Gender Equality, Integration and Social Affairs, 2015, p. 25.

3 E Paasche, S Plambech and M L Skilbrei, Assistert retur til Nigeria, University of Oslo, Oslo, 2016. 